\title{
Correction to: Clinical Observations and the Anatomical Basis of Blindness After Facial Hyaluronic Acid Injection
}

\author{
Lei Zhang ${ }^{1} \cdot$ Lei Pan $^{1} \cdot$ Hong $\mathrm{Xu}^{1} \cdot$ Sheng $\operatorname{Yan}^{1} \cdot$ Yi Sun ${ }^{1} \cdot$ Woffles T. L. Wu ${ }^{1,2}$ • \\ Sufan $\mathrm{Wu}^{1}$ (1)
}

Published online: 8 July 2020

(C) The Author(s) 2020

\section{Correction to: Aesth Plast Surg (2019) 43:1054-1060 https://doi.org/10.1007/s00266-019-01374-w}

The article Clinical Observations and the Anatomical Basis of Blindness After Facial Hyaluronic Acid Injection, written by Zhang et al was originally published Online First without Open Access. After publication in volume 43, issue 4, page 105-1060, the author decided to opt for Open Choice and to make the article an Open Access publication. Therefore, the copyright of the article has been changed to (C) The Author(s) 2020 and the article is forthwith distributed under the terms of the Creative Commons Attribution 4.0 International License (http://creativecommons. org/licenses/by/4.0/), which permits use, duplication, adaptation, distribution and reproduction in any medium or format, as long as you give appropriate credit to the original author(s) and the source, provide a link to the Creative Commons license, and indicate if changes were made.

Publisher's Note Springer Nature remains neutral with regard to jurisdictional claims in published maps and institutional affiliations.
The original article can be found online at https://doi.org/10.1007/ s00266-019-01374-w.

\section{Sufan Wu}

sufanwu@163.com

1

\footnotetext{
Department of Plastic and Reconstructive Surgery, Zhejiang Provincial People's Hospital, People's Hospital of Hangzhou Medical College, Hangzhou 310014, China
}

2 Woffles Wu Aesthetic Surgery, Camden Medical Centre, 1 Orchard Boulevard, Suite 09-02, Singapore 248649, Singapore 